\title{
Storing System dalam Meningkatkan Kelancaran Operasional Barang di Discovery Kartika Plaza Hotel Bali
}

\author{
Kadek Yuli Pramawati, Ni Made Ary Widiastini, Nyoman Dini Andiani \\ Undiksha
}

\begin{abstract}
Abstrak
Sistem penyimpanan barang sangat penting dilakukan pada setiap perusahaan karena dapat membantu dalam meningkatkan kelancaran operasional barang. Penelitian ini bertujuan untuk mengetahui bagaimana sistem penyimpanan yang diterapkan pada Discovery Kartika Plaza Hotel. Sumber data penelitian diperoleh dengan mengadakan observasi dan wawancara langsung dengan narasumber pada bagian store di Discovery Kartika Plaza Hotel. Hasil penelitian dimasukkan secara deskriptif dan diperoleh hasil yang menunjukkan bahwa dalam penyimpanan dan pengeluaran barang sudah menerapkan sistem penyimpanan dan prosedur yang telah ditetapkan yaitu dengan sistem First Expired First Out (FEFO) dan sistem First In First Out (FIFO). Masalah yang sering dihadapi yaitu kehilangan barang yang digunakan oleh departemen lain tanpa disertai formulir permintaan pengeluaran, oleh karena itu cara penanganan yang dapat dilakukan adalah selalu mengecek keadaan barang dan menyiapkan urgency form untuk mengambil barang diluar jam operasional store, sehingga kegiatan operasional barang untuk kebutuhan hotel dapat dilaksanakan dan berjalan dengan baik.
\end{abstract}

Kata kunci: Storing System, Operasional, Discovery Kartika Plaza Hotel dan Penanganan

\begin{abstract}
Stroring systems are very important to each company or hotel because it can help in improving the operational smooth of the stock. This research aims to find out how the storing system is applied in Discovery Kartika Plaza Hotel. The source of the research data obtained by conducting observations and interviews directly with the respondents in the store section of Discovery Kartika Plaza Hotel. The results of the study were inserted descriptively and obtained results indicating that in the storage and distribution of stock have implemented the storing system and procedures that have been established namely with First Expired First Out (FEFO) and First In First Out (FIFO) systems. The most common problem is the loss of stock used by other departments without an issued request form, therefore the way of handling that can be done is to always check the stock and prepare the emergency form to take the stock outside store operating hours, so that the operational activities of stock for hotel needs can be implemented and run well.
\end{abstract}

Keywords: Storing System, Operational, Discovery Kartika Plaza Hotel and Handling

\section{Pendahuluan}

Discovery Kartika Plaza Hotel merupakan hotel bintang lima yang dimiliki dan dikelola oleh PT. Kharisma Arya Paksi (PT. KAP) yang berlokasi di JI. Kartika Plaza, Kuta Selatan - Bali, terletak di Desa Tuban, Kecamatan Kuta 
Selatan, Provisi Bali. Sebelah utara Bandara Internasional Ngurah Rai dengan tempat yang strategis, dan bersebelahan dengan Discovery Shopping Mall yang merupakan fasilitas shopping mall dari Discovery Kartika Plaza Hotel. Discovery Kartika Plaza Hotel menawarkan jaya pelayanan akomodasi, jasa pelayanan makanan dan minuman, jasa pelayanan transportasi, ruangan untuk pertemuan, menyewakan tempat untuk berbagai event dan jasa pelayanan lainnya guna menunjang kebutuhan tamu atau wisatawan.

Dalam suatu usaha perhotelan, selain penjualan kamar dan pelayanan makanan serta minuman, hotel juga tidak terlepas dari kebutuhan barang-barang dan bahan-bahan makanan untuk menunjang operasional usaha tersebut. Penerimaan barang tersebut merupakan tanggung jawab dari bagian receiving dimana sebelumnya pengadaan atau pembelian barang tersebut dilakukan oleh bagian purchasing sesuai dengan permintaan setiap outlet di setiap departemen yang dibutuhkan. Kemudian barang tersebut diterima atau disimpan oleh bagian storing. Agar persediaan bahan-bahan dan barang-barang tersebut cukup dengan kehilangan yang rendah dikerenakan pencurian dan kerusakan. Maka perlunya kerjasama antara purchasing, receiving dan storing atau storekeeper. Berdasarkan latar belakang tersebut maka rumusan masalah dalam penelitian ini yaitu: (1) Bagaimana Storing System di Discovery Kartika Plaza Hotel. (2) Apa masalah yang dihadapi dalam meningkatkan kelancaran operasional barang. (3) Bagaimana cara menangani masalah yang dihadapi dalam meningkatkan kelancaran operasional barang. 


\section{Kajian Pustaka}

\subsection{Sistem Penyimpanan Barang di Store Hotel}

Store atau gudang merupakan salah satu tempat untuk menyimpan barang dan bahan makanan. Barang persediaan harus disimpan dan dirawat dengan baik oleh seorang karyawan yang bertugas di bagian store/gudang. "Setiap gudang dipimpin oleh seorang kepala gudang (storekeeper) yang klasifikasi jabatannya supervisor mengingat tanggung jawabnya yang besar dan penting" (Suarsana, 2007:130). Gudang sangat penting keberadaannya dalam suatu perusahaan atau hotel, karena dapat lebih mudah dalam proses kerja. Selain itu agar persediaan barang dan bahan kebutuhan operasional hotel tersedia dengan cukup dan resiko kerusakan dan kehilangan yang sedikit. Dengan adanya kebutuhan operasional hotel maka barang dan bahan harus selalu dalam keadaan baik, cara yang dapat dilakukan adalah dengan menerapkan sistem dalam penyimpanan barang. Erqorni (2009) sistem manajemen penyimpanan adalah pengelolaan dari segala aktifitas yang berkaitan dalam aktifitas penyimpanan barang sementara.

Sistem yang dapat diterapkan seperti Sistem FIFO (First In First Out) dan Sistem LIFO (Last In First Out) atau yang sering disebut dengan Sistem FEFO (First Expired First Out). "Keluar masuknya barang-barang diatur dengan sistem FIFO atau First In First Out' (Richard Sihite 2005 : 8). Sistem FIFO (Fisrt In First Out) merupakan suatu sistem penyimpanan dimana barang yang terlebih dahulu dimasukkan juga dikeluarkan terlebih dahulu, hal ini dilihat dari jenis barang atau bahan yang akan disimpan yang kurang tahan lama maka harus cepat dikeluarkan atau digunakan agar tidak rusak atau melewati batas waktu penggunaan serta menjaga kualitas barang dan bahan yang akan digunakan. Sistem FEFO (First Expired First Out) merupakan sistem penyimpanan barang dimana barang yang terakhir dimasukkan adalah barang yang pertama dikeluarkan, karena melihat batas waktu penggunaan bahan makanan atau barang tersebut yang lebih cepat.

\subsection{Strategi Penyimpanan Barang yang Efektif di Store Hotel}

Penyimpanan barang di gudang atau store tidak hanya sebatas menyimpan dan mendistribusikannya ke outlet-outlet lain yang ada di hotel, namun juga 
dibutuhkan strategi agar penyimpanan dan pendistribusian dapat berjalan dengan efektif.

Sesuai dengan penelitian yang telah dilakukan oleh Nurjanah, Ita dan Putri, Yuliani (2018) dengan judul penelitian " Upaya General Store Section dalam Menciptakan Kepuasan Pelanggan (Studi Pengendalian Mutu The Phoenix Hotel Yogyakarta), mengemukakan hasil penelitiannya yaitu upaya yang dilakukan oleh general store dengan cara mengusahakan stok barang kebutuhan hotel agar tetap terjaga, mengecek barang yang datang dalam keadaan baik, membedakan perlakuan penyimpanan barang, penulisan bin card yaitu formulir berisi nama barang dan dengan menggunakan metode FIFO (First In First Out) dalam pengambilan barang.

Strategi penyimpanan barang juga dapat dilakukan dimulai dengan mengatur tempat penyimpanan barang, barang yang ditata dengan rapi dan teratur dapat memudahkan saat pengambilan barang, juga dapat mengurangi kerusakan barang tersebut. Dengan memberi label pada setiap rak juga dapat mempermudah dalam pengambilan, karena seorang storekeeper hanya perlu membaca label barang yang akan diambil. Kemudian membuat daftar barang serta jumlah stok barang juga sangat penting, daftar barang yang berisi informasi mengenai jenis barang dan jumlah barang yang disimpan di gudang atau store didapatkan saat pergerakan keluar - masuk barang. Seorang storekeeper tidak hanya mencatat persediaan barang namun juga memperkirakan pergerakan stok barang atau membuat forecast. Pergerakan stok adalah jumlah persediaan yang dibutuhkan pada beberapa waktu kedepan, dengan menyiapkan jumlah persediaan barang yang cukup untuk periode berikutnya agar nantinya tidak terjadi kekurangan maupun kelebihan barang sehingga barang menumpuk dan cepat rusak.

Pada sistem komputer, setiap item diberikan kode mulai dari jenis barang, ukuran barang maupun warna dari barang tersebut. Dengan sistem komputer setiap aktifitas dalam gudang atau store akan tercatat dalam sistem sehingga membuat pekerjaan menjadi lebih cepat, menghemat waktu, tenaga dan juga biaya.

\subsection{Manfaat Storing System yang Baik}


Sistem penyimpanan barang yang baik sesuai dengan prosedur selain mempermudah dalam penyimpanan dan pengambilan atau pengeluaran barang juga memberikan manfaat bagi kelancaran operasional barang itu sendiri. Penyimpanan dilakukan agar barang atau bahan kebutuhan operasional yang dibutuhkan oleh pihak hotel atau perusahaan dapat tersedia dengan cukup, dimana tidak terjadi kekurangan barang maupun kelebihan barang di gudang serta dengan resiko kerusakan barang dan kehilangan barang yang kecil. Dengan adanya sistem dalam penyimpanan barang, maka barang yang cepat rusak atau memiliki batas waktu penggunaan yang cepat dan barang yang tahan lama dapat dibedakan baik dari segi penyimpanan maupun saat pendistribusiannya.

Sesuai dengan penelitian yang dilakukan oleh Kholifatun, Indri dan Nurcahyo, Jati (2018) dengan judul penelitian "Sistem Kerja Storage dan Purchasing Department terhadap Kelangsungan Operasional di Hotel Jambuluwuk Malioboro Yogyakarta" mengemukakan hasil penelitiannya yaitu bagian storage dan purchasing memiliki tanggung jawab baik dalam permintaan/pengadaan barang yang dibutuhkan, pembelian barang, penerimaan barang sampai dengan penyimpanan serta pendistribusian barang tersebut. Oleh karena itu, bagian purchasing dan storage harus bekerjasama dengan baik dalam menerapkan sistem yang telah ditetapkan untuk menciptakan hasil kerja yang memuaskan bagi tamu maupun hotel demi kelancaran operasional.

Sistem penyimpanan barang yang baik dapat dilihat dari jenis barang yang akan disimpan, suhu yang diperlukan dari setiap barang, jumlah barang yang akan disimpan dalam gudang serta kondisi gudang dalam keadaan baik atau tidak adanya kerusakan pada dinding maupun lemari atau tempat penyimpanan. Selain menjaga kualitas barang yang akan digunakan, sistem penyimpanan bertujuan untuk mempermudah dalam pencatatan data. Jika barang yang masuk dan keluar terarah dengan baik maka pencatatan data yang dilakukan juga akan berjalan dengan baik dan tepat.

Penelitian yang dilakukan oleh Rahman, Faisal dan Bagio, Tony Hartono (2004) dengan judul penelitian "Sistem Informasi Inventory dengan Menggunakan Metode FIFO (First In First Out), mengemukakan hasil penelitiannya mengenai metode yang digunakan yaitu metode FIFO agar 
memudahkan dalam pengawasan keluar masuknya barang serta pencatatan dan penentuan biaya bahan baku sebagai dasar penentuan harga pokok barang.

\section{Metode Penelitian}

\subsection{Rancangan Penelitian}

Penelitian ini dilaksanakan di Finance Department Discovery Kartika Plaza Hotel. Rancangan yang digunakan dalam penelitian ini adalah metode deskriptif kualitatif. Dimana penelitian ini akan memaparkan data yang sudah dikumpulkan melalui observasi dan wawancara secara langsung dengan para karyawan yang bertugas di store section mengenai sistem penyimpanan yang diterapkan di Discovery Kartika Plaza Hotel serta melakukan dokumentasi di lokasi penelitian yang nantinya data tersebut dapat dijadikan sebuah kesimpulan secara deskriptif yang berkaitan dengan rumusan masalah yang telah penulis buat.

\subsection{Hasil Penelitian dan Pembahasan}

\subsubsection{Finance Department}

Dalam finance department di Discovery Kartika Plaza Hotel terdapat struktur organisasi serta tugas dan tanggung jawabnya. Berikut struktur

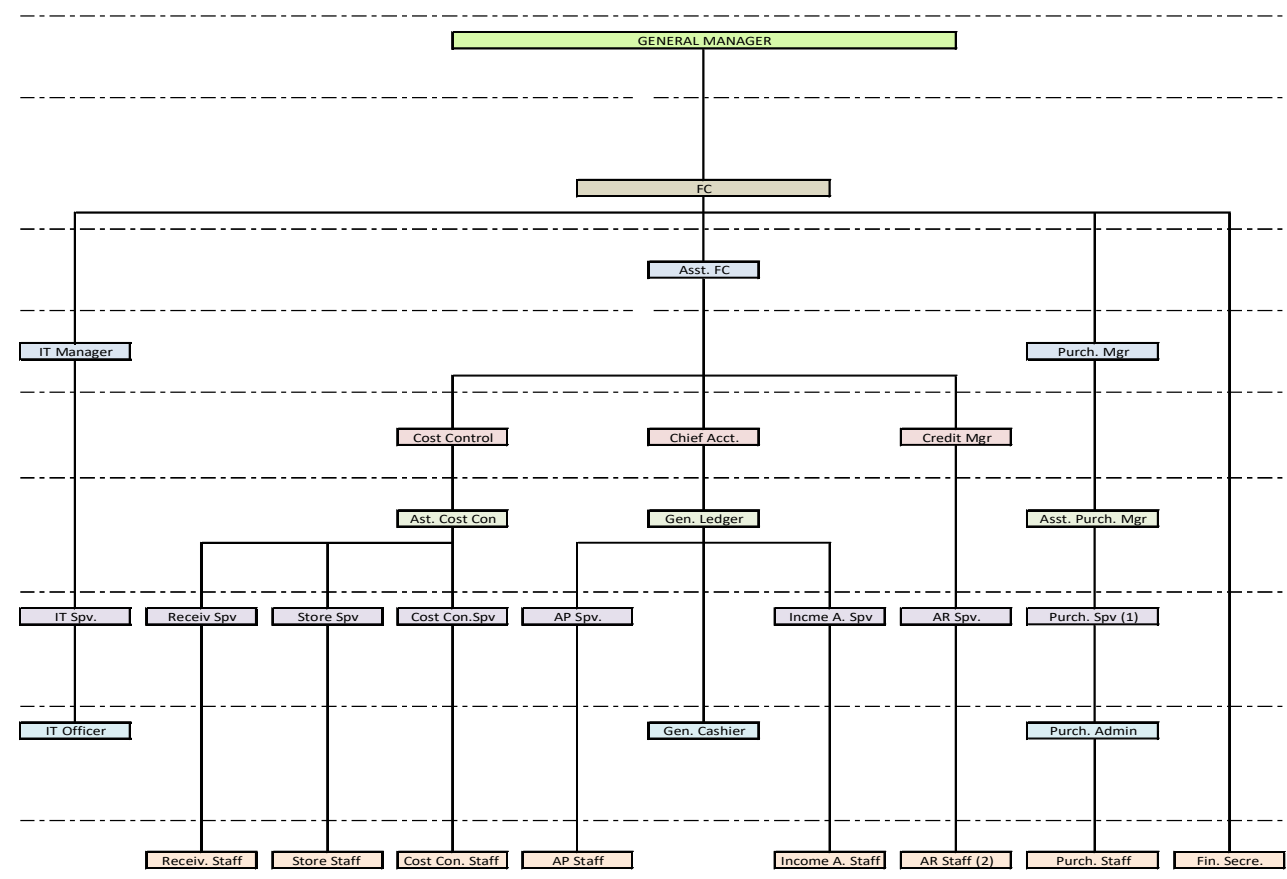

organisasi di finance department 
Bagan 1. Struktur Organisasi di Finance Department Discovery Kartika Plaza Hotel

Adapun tugas dan tanggung jawab yang harus dilaksanakan oleh setiap bagian yang ada di finance department seperti:

1. Finance Controller : Bertanggung jawab atas semua kontrol akuntansi dan keuangan hotel.

2. Asst. Finance Controller: Membantu dalam mengawasi, berkoordinasi dan berkomunikasi dengan departemen lain dalam hal keuangan.

3. Finance Secretary: Bertanggung jawab untuk memberikan layanan secretariat.

4. IT Manager. Bertanggung jawab atas pengawasan semua teknologi komputer.

5. Purchasing Manager. Bertanggungjawab terhadap pembelian produk atau jasa.

6. Cost Controller: Bertanggung jawab atas keseluruhan pelaporan akuntansi biaya.

7. Chief Accountant: Bertanggung jawab atas semua kontrol akuntansi dan keuangan hotel.

8. Credit Manager: Bertanggung jawab atas pengawasan, koordinasi dan pengendalian semua sistem dan prosedur yang berkaitan dengan pemrosesan dan persetujuan semua aplikasi kredit dan pengumpulan semua akun yang ada di hotel.

9. General Ledger. Bertanggung jawab untuk membantu dalam penyusunan laporan keuangan.

10. Receiving Supervisor. Bertanggung jawab untuk memeriksa dan menerima pengiriman barang.

11. Store Supervisor. Bertanggung jawab atas penyimpanan, pengeluaran, pengendalian dan menghitung bahan makanan, minuman dan persediaan umum di ruang penyimpanan.

12. Cost Control Supervisor: Bertanggung jawab atas pelaporan akuntansi biaya makanan \& minuman. 
13. Account Receivable Supervisor: Bertanggung jawab dalam posting dan penagihan semua piutang hotel.

Jurnal Manajemen Perhotelan Dan Pariwisata | 29 
14. IT Officer: Bertanggung jawab atas pengawasan semua teknologi komputer.

15. General Cashier: Bertanggung jawab untuk mencatat transaksi.

16. Receiving Staff: Bertanggung jawab untuk memeriksa dan menerima pengiriman barang.

17. Store Staff: Membantu tugas dari Store Supervisor dalam penyimpanan, pencatatan dan pengeluaran barang di gudang.

18. Cost Controll Staff: Membantu tugas Cost Control Supervisor atas pelaporan akuntansi biaya makanan \& minuman.

19. Account Payable Staff: Bertanggung jawab dan mengontrol semua voucher dan cek serta mencatatnya.

20. Income Audit Staff: Bertanggung jawab atas pemeriksaan atau pencatatan seluruh penjualan.

21. Account Receivable Staff: Bertanggung jawab dalam proses pemostingan dan penagihan piutang dari hotel.

\subsubsection{Storing System yang Diterapkan}

. Pengadaan barang kebutuhan hotel dilakukan oleh bagian purchasing yang bertugas melakukan pemesanan atau pembelian ke berbagai pemasok menurut barang / produk yang dibutuhkan. Barang yang telah dipesan dan dibawakan oleh pemasok ke hotel diterima oleh bagian receiving untuk dilakukan pengecekan baik dari segi kualitas barang dan kuantitas barangnya apakah telah sesuai dengan daily market list (daftar pembelian dengan frekuensi pemesanan hampir setiap hari) maupun purchase order (daftar pembelian dengan batas waktu kedatangan hingga satu bulan) yang terlebih dahulu dibuat oleh bagian purchasing. Barang yang telah diterima oleh receiving akan disimpan oleh storekeeper. Storekeeper memiliki berbagai jenis store atau ruang penyimpanan dalam menyimpanan barang / produknya, yang pertama yaitu food store untuk menyimpan barang / bahan makanan seperti sereal, saus, beras, yang kedua yaitu beverage store untuk menyimpan berbagai jenis minuman baik bersuhu ruangan seperti air kemasan, wine, sirup maupun bersuhu dingin seperti jus dan yogurt, yang ketiga yaitu general store untuk menyimpan barang kebutuhan administrasi maupun bahan-bahan kimia, dan ruang penyimpanan keempat yaitu engineering store untuk menyimpan barang yang dibutuhkan untuk perbaikan di hotel. Banyaknya ruang penyimpanan yang disediakan bertujuan untuk 
memisahkan berbagai jenis barang, hal ini dikarenakan material yang dikandung pada setiap barang berbeda. Sehingga, jika seluruh barang dijadikan satu dalam penyimpanan maka besar kemungkinan akan terjadinya kontaminasi antar barang. Berikut ruang penyimpanan barang
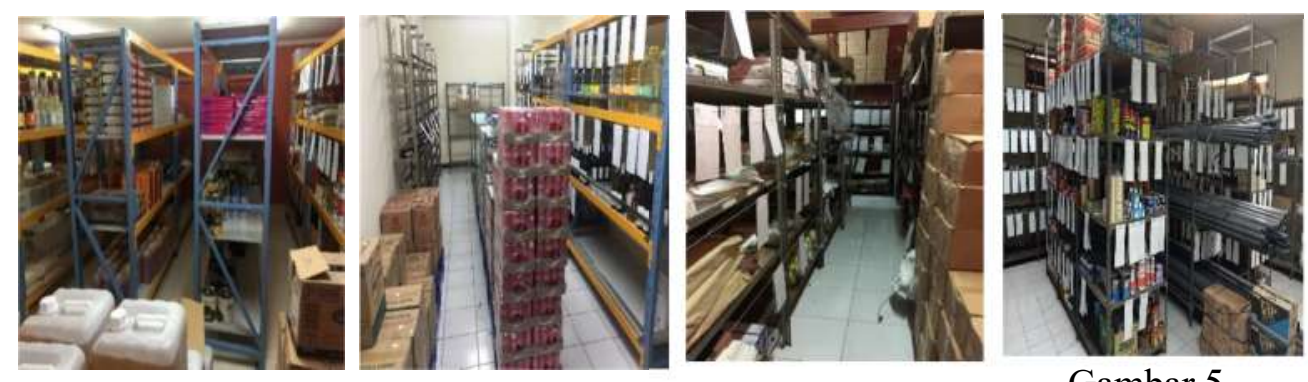

Gambar 5.

Engineering Store

Storing system yang diterapkan adalah dengan sistem FEFO (First Expired First Out) dan sistem FIFO (First In First Out). Sistem First Expired First Out, Barang yang datang dan disimpan selain melihat dari segi jenis barangnya juga dilihat

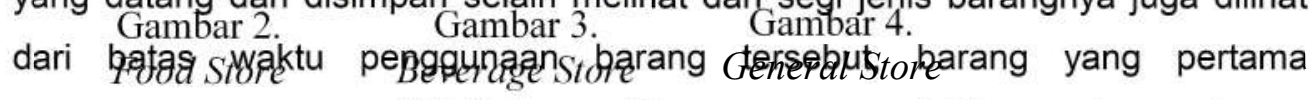
kadaluwarsa atau memiliki batas waktu penggunaan lebih cepat yang harus pertama keluar untuk didistribusikan seperti saus tomat. Sedangkan barang yang tidak memiliki batas waktu penggunaan seperti printer, kertas, pembungkus plastik, tinta menggunakan sistem First In First Out, karena barang yang pertama masuk harus terlebih dahulu digunakan daripada barang yang baru datang agar barang pertama tidak rusak sebelum digunakan dan rusak karena terlalu lama disimpan.

Pendistribusian barang tidak sekedar memberikan barang pada pengguna atau user namun terdapat prosedur dalam pengambilan barang. Prosedur yang diterapkan yaitu user yang akan mengambil barang harus membawa formulir atau issued request yang telah dilengkapi dengan tanda tangan manager atau supervisor dari departemen yang bersangkutan serta outlet yang menggunakan barang / produk tersebut. Berikut contoh issued request form. 


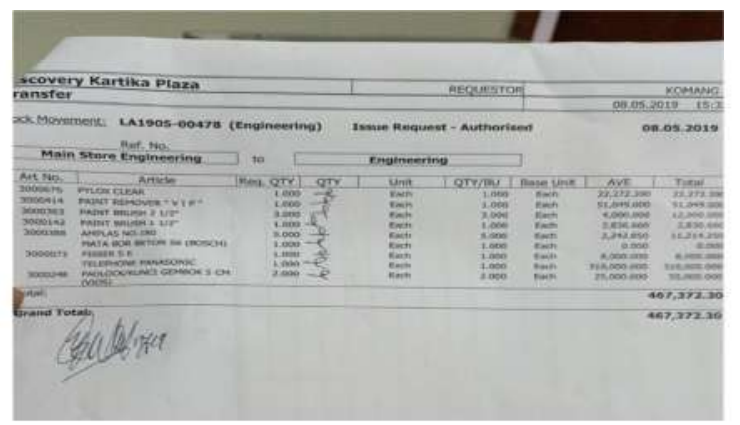

Gambar 6. Issued Request Form

Jam kerja operasional store adalah setiap Senin - Jumat, jadwal pengambilan barang store baik pada food store dan beverage store dibuka pada pukul 10.00 sampai dengan 16.00 WITA. Jadwal pengambilan barang di engineering store dibuka pada pukul 10.00 sampai dengan 13.00 WITA, sedangkan jadwal pengambilan barang di general store dibuka pada pukul 09.00 sampai dengan16.00 WITA. Untuk jadwal pengambilan bahan kimia atau chemical dibuka pada pukul 10.00 pagi sampai dengan 16.00 sore, Selasa jadwal pengambilan untuk housekeeping, Rabu jadwal pengambilan untuk steward dan Jumat jadwal pengambilan untuk houskeeping steward. Dalam dunia usaha terkhusus pada dunia perhotelan, kebutuhan hotel maupun kebutuhan tamu yang terjadi secara mendadak pasti sering dialami, kebutuhan baik dari segi barang maupun bahan makanan untuk kelancaran operasional hotel itu harus dapat dipenuhi dengan baik. Untuk pengambilan barang urgent atau barang yang dibutuhkan secara mendadak maupun barang untuk tamu vip diluar jadwal yang telah ditentukan maka user harus membawa emergency request yang telah disetujui oleh dept head, finance controller, executive manager.

Issued request dan emergency request sangat penting keberadaannya. Jumlah barang yang diminta akan dimasukkan atau di transfer ke setiap departemen pada sistem komputer bertujuan untuk memberikan biaya atau charge terhadap departemen yang menggunakan barang tersebut.

Barang yang tersimpan di store akan dicek secara berkala baik setiap hari maupun setiap bulan, kegunaan mengecek barang setiap hari adalah agar mampu mendeteksi adanya kerusakan maupun barang yang memiliki kadaluwarsa lebih awal, sedangkan mengecek setiap bulan digunakan untuk mengecek dan memastikan persediaan barang baik di store maupun setiap 
outlet. Pengecekan persediaan barang setiap bulan disebut dengan inventory. Setelah melakukan pengecekan persediaan barang, kemudian dilakukan pemasukan data-data ke sistem komputer bertujuan untuk menyeimbangkan jumlah persediaan barang fisik dan jumlah barang di sistem. Inilah yang dijadikan acuan oleh storekeeper pada saat membuat purchase request (proses untuk membuat suatu permintaan pembelian atau pengadaan barang) .

\subsubsection{Masalah yang Dihadapi dan Cara Penanganan oleh Storekeeper}

Permasalahan pertama adalah user yang mengambil barang tanpa membawa issued request maupun emergency request. Biasanya user mengambil barang diluar jam operasional store sehingga storekeeper tidak mengetahui barang tersebut diambil oleh user. Cara menangani permasalahan ini adalah storekeeper dapat menyediakan urgency form yang telah disediakan di store masing-masing, digunakan untuk mencatat barang yang akan diambil oleh user dan mengharuskan user membuat emergency request yang telah diberikan ijin oleh finance controller dan cost control serta dengan persetujuan general manager, department head yang bersangkutan, storekeeper dan didampingi oleh security pada saat pengambilan barang. Jika permasalahan ini sering dilakukan oleh user maupun departemen secara terus menerus maka harus segera ditinjak lanjuti, karena bagaimanapun juga prosedur yang diterapkan harus dilakukan dengan baik

Permasalahan kedua yaitu nama barang yang diminta oleh user pada issued request sering mengalami kesalahan. Kesalahan terjadi dikarenakan nama barang yang hampir sama namun dengan berat atau spesifikasi yang berbeda. Hal yang dapat dilakukan oleh storekeeper yaitu mengganti nama barang secara manual pada sistem pada saat memposting, karena jika nama barang yang diposting menyesuaikan dengan nama barang dari user maka pada sistem tidak terdeteksi atau postingan akan berwarna merah dan biaya barang yang diambil tidak masuk ke departemen yang ditujukan.

Permasalahan ketiga adalah kekurangan tenaga storekeeper pada saat barang datang secara bersamaan dalam jumlah yang banyak. Permasalahan ini dapat ditangani dengan cara menata barang fokus pada satu barang, kemudian

jika barang tersebut telah tersusun dengan baik, dilanjutkan dengan menata 
barang kedua, kemudian dapat meminta tenaga storekeeper lainnya untuk membantu menata barang dan penataan dapat dilakukan selain di hari / jadwal pengambilan barang tersebut.

\section{Penutup}

1. Sistem penyimpanan yang diterapkan pada Discovery Kartika Plaza Hotel adalah sistem FIFO (First In First Out) dan sistem FEFO (First Expired First Out). Tempat penyimpanan barang yang ada dibagi menjadi 4 jenis, yaitu Food Store, Beverage Store, General Store dan Engineering Store.

2. Masalah yang sering dialami oleh bagian store adalah kehilangan barang dikarenakan user tidak mengikuti prosedur yang berlaku seperti membawa issued request dan emergency request form sebagai permohonan ijin mengambil barang yang dibutuhkan. Kekurangan tenaga storekeeper juga menjadi permasalahan dikarenakan jumlah yang bertugas pada satu store hanya ada satu orang.

3. Cara yang dapat dilakukan dalam mengatasi masalah adalah dengan mengecek barang secara berkala agar tidak terjadi kehilangan yang terlalu lama, serta selalu menata barang dengan baik dan rapi sesuai dengan sistem yang telah diterapkan sehingga memudahkan dalam pendistribusian.

\section{Daftar Pustaka}

Elqorni Ahmad, 2009. Pengertian Sistem Manajemen Pergudangan. https://elqorni.wordpress.com/2009//11/11/sistem-manajemen-gudang/. Diakses pada tanggal 8 April 2019.

Kholifatun, Indri dan Nurcahyo, Jati. 2018. "Sistem Kerja Storage dan Purchasing Department terhadap Kelangsungan Operasional di Hotel Jambuluwuk Malioboro Yogyakarta". file:///C:/Users/username/Downloads/3637-101531-PB.pdf. Diakses pada tanggal 8 April 2019.

Nurjanah, Ita dan Putri, Yuliani. 2018. "Upaya General Store Section dalam Menciptakan Kepuasan Pelanggan (Studi Pengendalian Mutu The Phoenix Hotel Yogyakarta". https://osf.io/pukqm. Diakses pada tanggal 8 April 2019.

Rahman, Faisal dan Bagio, Tony Hartono. 2004. "Sistem Informasi Inventory dengan Menggunakan Metode First In First Out (FIFO)". https://www.researchgate.net/profile/tony bagio/publication/266411389 sist em informasi inventory dengan menggunakan metode first in first out fifo/links/581321af08aeb720f680d7c4/sistem-informasi-inventory-dengan- 
menggunakan-metode-first-in-first-out-fifo.pdf. Diakses pada tanggal 8 April 2019.

Sihite, Richard, 2000. Hotel Accounting and Cashier.Surabaya:SIC.

Suarsana, Nyoman. 2007. Siklus Pengadaan Barang Aplikasi di Perhotelan dan Restoran. Yogyakarta: Graha IImu. 